\title{
Características do Ensino Superior de Graduação em Turismo: a organização do conhecimento como critério de planejamento da formação profissional
}

\author{
Characteristics of Graduate Tourism Courses: \\ the organization of knowledge as criterion for planning \\ the professional formation
}

\section{Lucia Onzi \\ Sílvio Paulo Botomé $\hat{e}^{2}$}

\begin{abstract}
RESUMO: A educação, no Brasil, vem passando por mudanças que podem não estar sendo efetivas devido, também, à pouca clareza dos termos utilizados nas novas diretrizes. Isso indica a necessidade de investigar o que está ocorrendo em relação à formação de nível superior em Turismo, pois os profissionais irão intervir em um determinado campo a partir do que aprenderem nos cursos que freqüentarem. Para isso foram examinadas as grades curriculares de quatro cursos de graduação em Turismo. As disciplinas foram agrupadas em categorias de formação de acordo com características observadas nos nomes das mesmas. Os resultados são: uma organização do currículo a partir das características encontradas nos nomes das disciplinas e que revelam o foco em assuntos nos mais variados graus de profundidade e abrangência, o que indica o desenvolvimento de aprendizagens limitadas e pouco significativas socialmente; a indicação de diferentes categorias de aprendizagem, baseadas em critérios definidos pelo tipo de atuação a ser desenvolvida e não pelo tipo de informação a ser apresentada.
\end{abstract}

PALAVRAS-CHAVE: formação profissional em turismo; planejamento de ensino de turismo; currículo de graduação em turismo.

1. Graduada em Turismo pela PUC-RS e mestre em Psicologia pela Universidade Federal de Santa Catarina. Contato: Rua Dr. Montaury, 1478/501 - 95020-190 - Caxias do Sul - Rs; e-mail: luonzi@hotmail.com.

2. Graduado em Psicologia pela PUC-SP, mestre e doutor em Psicologia pela USP. Professor titular do departamento de Psicologia da Universidade Federal de Santa Catarina. Contato: Rua das Acácias, 464 - 88040-560 - Florianópolis - sc; e-mail: botome@cfh.ufsc.br. 
ABSTRACT: Education, in Brazil, has been going through changes which might not be effective due to the little clarity of the terms used in the new guidelines. That indicates the need to investigate what is happening in relation to graduation in courses of Tourism, because the professionals will intervene in a determined field from what they have learned during the courses. This research consists of an examination of the syllabuses of four university courses of Tourism. The disciplines were gathered in categories of formation according to characteristics observed in the names of these disciplines. The results were: an organization of the curriculum from the characteristics found in the names of the disciplines which reveled the focus on subjects with various degrees of depths and comprehensiveness, what indicates the development of socially less meaningful and limited learning; the indication of different categories of learning, based on criteria defined by the kind of actuation to be developed and notby thekind of information to be presented.

KEYWORDS: professional formation in tourism; teaching planning of tourism; curriculum of graduation in tourism.

\section{Introdução}

O currículo de um curso de formação profissional, principalmente de nível superior, é uma espécie de projeto do profissional dos próximos vinte ou trinta anos. Botomé (1988) chama a atenção para isso quando discute as possibilidades da Psicologia como área de conhecimento e como campo profissional. Em relação ao Turismo, não é diferente. Os profissionais que passarem por cursos de graduação nessa área irão atuar e, dessa forma, definir o que será a profissão de acordo com o que aprenderam nos cursos que freqüentaram. Isso leva a ser importante identificar, nos currículos, o que está sendo definido como papel dos profissionais agentes do turismo ${ }^{3}$, ou seja: Que atuações estão sendo garantidas pelo processo formativo de nível superior nesse campo? Qual é o projeto do profissional que está em questão nos cursos de graduação em Turismo? Que tipo de intervenção profissional esses cursos estão possibilitando? É possível identificar na grade curricular dos cursos de Turismo as aprendizagens características dos agentes do turismo ou os comportamentos profissionais que precisam ser desenvolvidos durante os cursos de graduação e que irão definir o papel social deste profissional?

3. Expressão utilizada para se referir a todos os profissionais do turismo e não somente aos que trabalham em agências de viagens e turismo.
Aprender pressupõe mudança de comportamento (Gagné, 1971; Postman \& Weingartner, 1978; Mager, 1987; Kubo \& Botomé, 2001a), seja no sentido de adquirir novos comportamentos ou no de melhorar ou aperfeiçoar comportamentos já existentes antes do processo de ensino-aprendizagem. A partir disso, é possível afirmar que o principal objetivo da educação é modificar as relações entre a ação dos alunos e o meio em que estão inseridos ou, em outras palavras, modificar seus comportamentos. Em um contexto profissional, o meio em relação ao qual o organismo deverá agir é uma determinada realidade ou um "recorte" específico da realidade que precisa da intervenção de pessoas capazes para resolver ou minimizar os problemas e necessidades característicos de tal meio. Nesse sentido, os alunos, futuros profissionais, precisam aprender a agir em relação à determinada realidade e não apenas aprender disciplinas e "conteúdos".

Comportamento é conceituado como "uma complexa relação entre a ação do organismo e o meio" (Botomé, 2001), o que significa dizer que o comportamento é definido pela relação entre o que existia antes da ação do organismo, a ação do organismo e o que resulta ou deve resultar dessa ação. A noção de comportamento é utilizada por Botomé (2002) para esclarecer a definição do que é "competência", termo adotado a partir da reforma da Educação iniciada em 1996, mas que, pela falta de clareza em relação ao que significa, pode estar sendo usado de forma semelhante à do termo "objetivo comportamental" nas décadas de 1960 e 1970, mantendo os problemas de origem do conceito, que acabou sendo reduzido, dentre outras coisas, à proposição de atividades do aluno em contexto escolar ou à proposição das intenções do professor (Botomé, 1980). O autor define "competência" como um grau de perfeição na capacidade de atuar do profissional, ou seja, é uma característica do comportamento profissional em qualquer campo. O processo inicia a partir da informação que deve ser transformada em aptidão, competência, habilidade e perícia, sendo que essas quatro últimas palavras são graus da capacidade de atuar, de acordo com o exame de Botomé (2002), e não fenômenos diversos entre si.

É importante esclarecer que comportamento é mais do que algo visível ou definido por uma ação (ou classe de respostas) observável. O comportamento é constituído pela relação entre ações de um organismo e duas instâncias do meio em que atua: aquela que existe antes dessa ação e o que decorre, resulta ou se segue a essa mesma ação. Nesse sentido, cada comportamento é uma complexa interação com o meio, nada simples ou fácil de nomear e que necessita de evidências do que sejam os componentes dessa interação para ser efetivamente identificado. De acordo com o conhecimento produzido pelo Behaviorismo Radical, que tem no pensamento de B. F. Skinner seu principal ponto de referência, pensar, por exemplo, é um processo comportamental e não é algo facilmente observável de maneira direta por 
outras pessoas. Isso possibilita afirmar que escolher e decidir também são comportamentos, porém só são perceptíveis os produtos de tais processos e não as relações que as pessoas estabelecem ao decidir ou escolher. Essas considerações servem para chamar a atenção para algumas características e possibilidades relacionadas ao fazer humano, que nem sempre pode ser observado diretamente enquanto está ocorrendo, mas pode ser identificado a partir de seus componentes: as circunstâncias em que a ação ocorre, as características dessa ação e as decorrências dela.

Para fazer referência a certos comportamentos que não podem ser observados diretamente, é importante procurar expressá-los com base no que eles produzem em relação ao ambiente ou então a partir do uso de termos que revelem da maneira mais clara possível o que precisa ser observado para poder inferir que tal comportamento ocorreu ou está ocorrendo. Em relação a isso é comum encontrar em livros, nos quais os autores propõem uma discussão a respeito da formação do profissional em turismo ${ }^{4}$, a enumeração de habilidades requeridas do profissional, descritas de uma maneira que encobrem os comportamentos, ou melhor, os resultados que precisam ser identificados no ambiente para poder identificar de fato a existência de tais habilidades. Nesses livros, uma das habilidades listadas diz que o aluno deve "aprender a aprender", por exemplo. Habilidades como "inclinação e vocação para lidar com o sentimento das pessoas", "ser criativo e inovador", "mostrar capacidade de avaliar situações" etc., também são citadas como importantes para que o profissional tenha condições de ingressar e se manter no mercado de trabalho do turismo. Mas de que forma os professores podem ensinar os seus alunos a aprender constantemente? E a "ter" inclinação e vocação? São efetivamente "habilidades"? Ou ainda, não são expressões confusas para delimitar "o que alguém precisa ser capaz de realizar"?

Essas expressões são pouco adequadas para descrever os processos comportamentais que estão envolvidos na aquisição de um padrão de atuação. Desenvolver nos alunos a capacidade de aprender a aprender, por exemplo, é um dos principais objetivos da Educação de uma maneira geral e um padrão de comportamento que o aluno deverá desenvolver durante todo o processo formativo, a partir da maneira como a relação entre ensino e aprendizagem for planejada e conduzida pelo professor (foco na ação do aluno e não na do professor; desenvolvimento constante e gradual, de acordo com o ritmo do aluno; possibilidade de refazer tarefas para corrigi-las ou aperfeiçoá-las; ênfase na pesquisa e produção de conhecimento, uso da Lógica como recurso para pensar). A mesma reflexão serve para a expressão "inclinação e vocação". O que é considerado como vocação

4. Ver Trigo (1998); Ansarah (2002); Spinelli (2002). para uma profissão ou tipo de intervenção? Por quais tipos de situações o aluno deve passar para que possa desenvolver a vocação de lidar com o sentimento das pessoas? Essas "situações" precisam ser definidas, planejadas e vivenciadas durante o processo de formação sob a forma de comportamentos dos aprendizes. $O$ aluno aprenderá a se comportar de acordo com o que é esperado em um campo profissional se os comportamentos definidores desse campo forem identificados e bem descritos, e não encobertos em termos e expressões que podem ser envolventes, porém vagos e não esclarecedores do que precisa ser feito como responsabilidade do profissional formado.

Trigo (1998), ao examinar a capacitação profissional em turismo na sociedade do século XXI, caracteriza o que chama de "sociedade pós-industrial" e estabelece algumas relações entre aspectos dessa sociedade e as necessidades de formação para que os profissionais do turismo possam atuar em tal contexto. $\mathrm{O}$ autor salienta que complexidade, mudança e dinamismo são características marcantes dessa realidade social. Ansarah (2002) faz considerações semelhantes, porém diretamente ligadas ao mercado de trabalho em turismo e ao "perfil" do profissional para atuar em tal mercado. Ambos reconhecem que os agentes do turismo, em função das características sociais e do mercado, precisam ser capacitados para atuar em um grau elevado de complexidade, o que significa dizer que eles devem ser capazes de apresentar uma grande quantidade e variedade de ações em relação a um meio amplo e em constante mudança. Isso pode contrastar com uma dúvida: os cursos de graduação em Turismo, da maneira como são planejados, estão desenvolvendo nos alunos as habilidades (como um grau de perfeição de suas ações) necessárias para atuar em um campo profissional com tais características? Paviani et al. (1993) avaliam as decorrências relacionadas aos projetos de cursos de graduação e chamam a atenção para os problemas da utilização, no âmbito escolar, das mesmas categorias criadas para organizar e sistematizar o conhecimento existente (áreas, subáreas e disciplinas, por exemplo) no âmbito da taxonomia utilizada pelas bibliotecas (os "almoxarifados" do conhecimento). Para os autores, as categorias criadas para organizar o conhecimento parecem insuficientes para provocar a transformação desse conhecimento em capacidade de atuar perante uma determinada realidade, nesse caso, profissional. A organização dos currículos dos cursos de Turismo talvez ainda não seja feita com os cuidados relativos a isso, o que pode estar limitando a formação e a conseqüente atuação desses profissionais.

O Plano Nacional de Educação que estabelece, entre outras coisas, a criação das Diretrizes Curriculares Nacionais ( $\mathrm{CNS}$ ) que devem orientar o planejamento dos cursos oferecidos pelas instituições de nível superior foi aprovado em 2001. Antes disso, o que orientava o planejamento dos cursos de graduação eram os Currículos Mínimos. As DCNs estabelecem competências e habilidades que devem 
ser aprendidas durante a formação, bem como os "conteúdos" curriculares que devem ser enfocados. O Currículo Mínimo estava baseado em disciplinas ou matérias profissionalizantes que, supostamente, seriam capazes de garantir o desempenho do aluno no exercício da profissão que escolheu. O objetivo, em ambos os casos, é preparar profissionais hábeis e competentes (em analogia ao que é proposto nas diretrizes), bem como "possuidores" do conhecimento necessário para exercer uma profissão. Mas é possivel identificar o "perfil" do profissional que será preparado em um curso de Turismo a partir do exame das disciplinas que compõem esse curso? A mudança de "conteúdos" para competências altera esse "perfil"?

Os cursos de graduação, planejados antes ou depois da reforma de 1996, devem estar organizados de forma que o profissional, ao final do processo formativo, seja capaz de comportar-se conforme o que foi minimamente estabelecido no projeto de cada curso. Para que isso ocorra, são definidas disciplinas ou matérias que, em conjunto, devem ser capazes de "desenhar o perfil" (mantendo a metáfora) do profissional em cada campo. É importante avaliar o conjunto de disciplinas que constituem os cursos de Turismo para identificar o que os nomes das disciplinas já indicam como aprendizagem característica do profissional agente do turismo. O exame das disciplinas oferecidas em cursos de Turismo de algumas universidades brasileiras pode fornecer informações relativas à importância que é dada a um ou outro conjunto de conhecimentos específicos de determinada disciplina, além de fornecer um panorama do que está sendo proposto como papel profissional ao aluno que passar pela formação nessas instituições. Cada disciplina, ou conjunto de disciplinas, deveria garantir a aprendizagem de determinado conjunto de comportamentos que são importantes para o exercício profissional no setor. Esse exame servirá para verificar se isso está ocorrendo e de que forma está ocorrendo.

\section{Método}

\section{Fontes de informação}

Foram utilizados como fontes de informação para examinar o que os cursos de Turismo estão desenvolvendo como aprendizagens dos alunos, futuros profissionais, planos e currículos de cursos de quatro diferentes universidades. Os critérios de escolha das instituições de ensino superior foram o tempo de existência do curso de Turismo ou a existência de produção e publicação científica na área. Foram selecionados cursos de Turismo em quatro universidades, localizadas em São Paulo, Curitiba, Florianópolis e Porto Alegre, que apresentaram pelo me- nos uma das características. Duas das instituições consultadas são públicas e gratuitas. Uma delas é responsável pela publicação da revista científica brasileira mais antiga e mais respeitada na área e o curso de Turismo foi implantado em 1973; na outra o curso de Turismo existe desde 1978. As outras duas universidades consultadas são particulares ou comunitárias e pagas. Uma delas também foi selecionada por ter criado o curso de Turismo em 1973; na outra, o curso teve início em 1990, e essa instituição publica a segunda revista científica sobre turismo existente no país.

\section{Procedimentos}

Os documentos (grades curriculares dos quatro cursos de Turismo selecionados para a pesquisa) foram examinados pela primeira vez sem um critério específico, mas em busca de características que permitissem o agrupamento das disciplinas em categorias comuns. A partir disso foram criadas categorias baseadas na avaliação do nome de cada disciplina. As disciplinas foram agrupadas em categorias, definidas a partir do exame do nome de cada disciplina e da possível relação que pode ser estabelecida com áreas ou subáreas de conhecimento específicas ou com atuações técnicas características do trabalho no campo profissional do Turismo. Exemplo disso são as disciplinas que enfocam a História (área de conhecimento) ou disciplinas que tratam de técnicas de agenciamento ou organização de eventos, que podem ser consideradas atividades específicas dos agentes do turismo. Em cada disciplina foi avaliada a relação entre o nome da disciplina, sua localização no curso ao longo dos semestres e a possível função da mesma na formação do agente do turismo. A partir disso foi feita uma avaliação das possíveis aprendizagens que estão sendo desenvolvidas nos cursos de graduação em Turismo.

\section{Resultados}

O exame do currículo dos cursos de Turismo de quatro diferentes universidades pode oferecer um panorama do que está sendo considerado relevante para a atuação dos profissionais que deverão intervir nesse campo. Características como diferentes enfoques, aprofundamento dado nessa ou naquela área ou as atribuições consideradas importantes para a intervenção desses profissionais podem ser reveladas a partir de possíveis agrupamentos observados no conjunto geral das disciplinas. Que categorias de formação específicas são comuns nos diferentes cursos? Quais são as mais representativas? De que maneira o aprofundamento de diferentes tipos de conhecimento pode afetar a formação e a atuação dos profissionais que pretendem ingressar no campo profissional do turismo? 
Na Tabela 1 é possível identificar as 19 categorias utilizadas para examinar o conjunto de disciplinas dos quatro cursos selecionados e a descrição de cada uma delas. $O$ total de disciplinas obrigatórias, a carga horária e o percentual equivalente a cada categoria na formação obrigatória das diferentes universidades também estão representados nesta tabela. O total referente ao número de disciplinas e carga horária obrigatória é diferente de uma universidade para a outra. Variações no número de disciplinas, carga horária e percentual em cada universidade ocorrem em todas as categorias de formação. Em algumas categorias, as variações são mais acentuadas do que em outras nas diferentes universidades, por exemplo, nas categorias de formação instrumental, formação histórica, formação geográfica, formação para planejamento, formação administrativa, formação promocional comercial e formação prática.

Em cada universidade, diferentes categorias possuem os percentuais mais representativos da formação total dos agentes do turismo. Na universidade F1, as categorias com o percentual mais alto são as de formação histórica e formação prática, que representam 13,3\% da formação total. Depois destas, as categorias de formação geográfica e de formação para planejamento representam $8,9 \%$ da formação total dos agentes do turismo no curso desta universidade. Na universidade F2, a formação para planejamento é a mais representativa, com 18\%, seguida da formação prática, com 16,9\% e da formação operacional comercial, com 10,1\% do total da formação em turismo. Na universidade P1 as categorias mais representativas são de formação instrumental e de formação para planejamento que representam 15,7\% do total do curso, seguidas das categorias de formação administrativa e de formação promocional comercial, com 7,9\%. Na universidade P2 a formação administrativa vem em primeiro lugar com $21 \%$, seguida das categorias de formação instrumental e de formação prática, com $16,4 \%$ e pela formação promocional comercial, com $8,7 \%$ do total da formação em turismo.

Algumas universidades não oferecem disciplinas obrigatórias para certos tipos de formação. É o caso da universidade F2, por exemplo, que não oferece disciplinas obrigatórias para formação histórica nem para formação pedagógica, somente disciplinas optativas. As universidades F1 e P2 não oferecem disciplinas nem obrigatórias, nem optativas para a categoria de formação psicológica. Disciplinas de formação pedagógica não são oferecidas como obrigatórias em nenhuma universidade. É possível cursá-las, como disciplinas optativas, na universidade F2.

Por que existem variaçōes tão significativas de uma universidade para a outra em relação à carga horária de um mesmo tipo de formação? Seria em função das características de cada organização universitária ou estaria de acordo com a concepção que cada uma tem em relação ao profissional que deseja formar? Tais diferenças refletem concepções diferentes a respeito do turismo e do profissional que nesta área

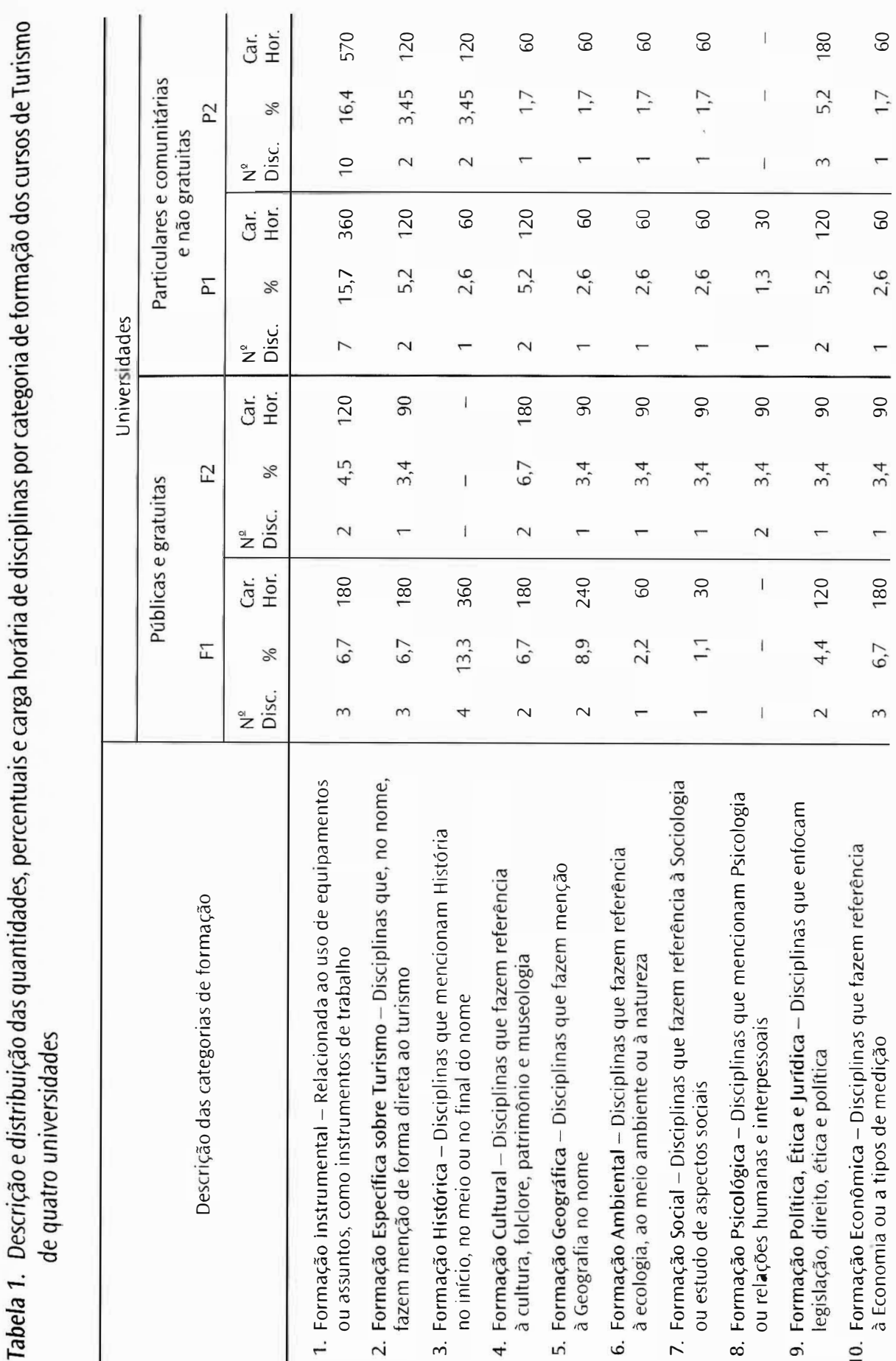




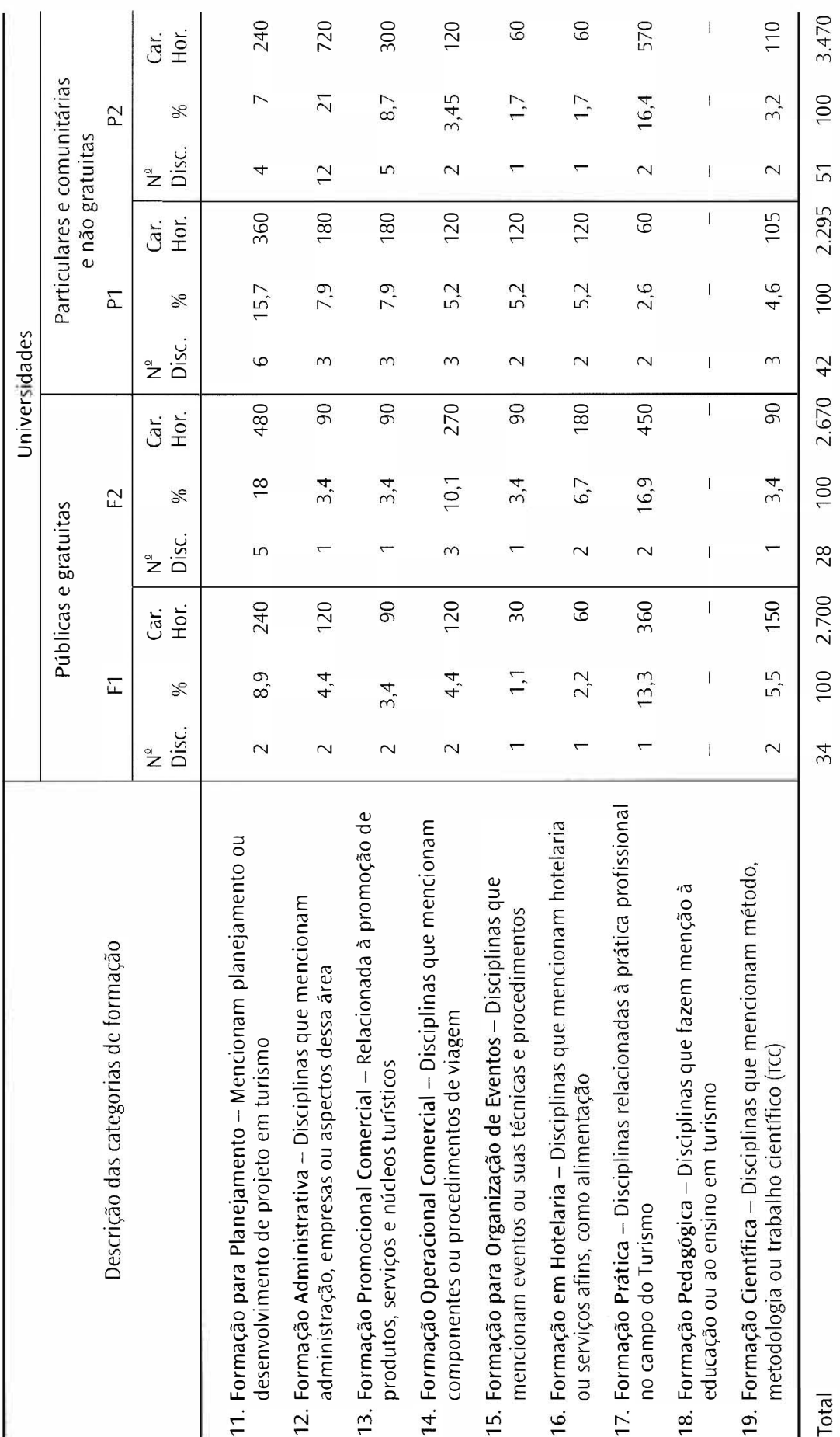

deve atuar ou refletem apenas as diferentes maneiras pelas quais os cursos são organizados e/ou os diferentes critérios utilizados para nomear suas disciplinas?

Esta análise não permite responder a tais questões, mas elas devem orientar um posterior exame de cada categoria em particular. Muitos podem ser os motivos que determinam as diferenças observadas de um curso para outro, e tais razões nem sempre estão claras, ou nem sempre podem ser as mais adequadas para orientar o planejamento de cada curso. A formação profissional de nível superior, adquirida durante um curso de graduação, é responsável por desenvolver o repertório comportamental dos alunos para que eles possam intervir, com um grau superior de qualidade, na realidade profissional em que estão prestes a ingressar. Esses comportamentos é que devem orientar o planejamento e a organização de cada curso ou, no caso, dos cursos de Turismo. Esse, porém, não parece ser um critério que possa ser adotado a partir da organização dos currículos que foi arrolada e examinada na Tabela 1.

O exame das categorias de formação que possuem os percentuais mais significativos em relação à formação dos profissionais do turismo, e que se repetem nas diferentes universidades, permite identificar o que é considerado nuclear para a formação desses profissionais. Os cursos parecem voltados para um tipo de atuação técnico-administrativa, pois a ênfase dos mesmos está nas categorias que se relacionam a comportamentos mais operacionais. Isso é percebido na ênfase dada à formação prática nas universidades F1 (13,3\%), F2 (16,9\%) e P2 (16,4\%). Formação para planejamento também aparece como uma das principais categorias nas universidades F1 (8,9\%), F2 (18\%) e P1 (15,7\%). Outras categorias relevantes nas diferentes universidades são formação instrumental (15,7\% em P1 e 16,4\% em P2); formação administrativa (7,9\% em P1 e $21 \%$ em P2); formação promocional comercial (7,9\% em P1 e 8,7\% em P2); e formação operacional comercial (10,1\% em F2), todas voltadas para o uso de ferramentas, técnicas ou conhecimentos próprios do turismo ou úteis para um tipo de intervenção direta no mercado de trabalho, $\mathrm{e}$ não como conhecimento que possa orientar a intervenção em problemas sociais relacionados ao fenômeno turístico e que definiriam, de maneira mais ampla e significativa, esse campo profissional. Disciplinas que enfocam conhecimentos de outras áreas, obtidos por meio de diferentes métodos e enfoques, podem possibilitar um tipo de atuação mais diversificada e necessária, mas não parecem ser consideradas um tipo de formação relevante para se trabalhar com turismo. Mesmo a formação para planejamento, que é enfatizada em três das quatro universidades examinadas, e que poderia orientar a atuação do profissional em todos os possíveis tipos de inserção, indica um tipo de intervenção voltada, principalmente, para a elaboração de estratégias para o uso dos recursos turísticos ou estimular a ocorrência de turismo em locais determinados. Se essas estratégias são sustentáveis ou não para a sociedade e para o meio ambiente, se enfocam os aspectos econômicos ou os 
interesses do mercado, não é possível identificar ainda. Mas um posterior exame de cada categoria em particular poderá fornecer algumas informações a esse respeito e esclarecer se, realmente, o foco mais intenso da formação está nos comportamentos técnicos, como parece ser o caso.

Algumas categorias, em certas universidades, podem estar sendo consideradas desnecessárias ou supérfluas para a formação dos agentes do turismo. É o caso da formação psicológica, que não aparece como formação obrigatória nas universidades F1 e P2; e da formação pedagógica, que aparece somente como formação optativa na universidade F2. Serão mesmo desnecessárias as aprendizagens relativas à psicologia ou à pedagogia para a atuação dos agentes do turismo? Ou a relação entre o turismo e essas áreas, ou campos de atuação, não foi suficientemente esclarecida? Essa situação não poderia dificultar a percepção de comportamentos profissionais em turismo que fossem baseados no conhecimento produzido por essas áreas, ou no tipo de intervenção característico de cada um desses campos? Os agentes do turismo não precisam ensinar nada a ninguém durante o exercício de sua profissão? Não precisam interpretar, estabelecer ou conduzir relações com outras pessoas? É provável que precisem, mas as categorias de formação psicológica e de formação pedagógica, responsáveis por desenvolver aprendizagens desse tipo, recebem pouca ênfase nos cursos. Ou até não recebem ênfase alguma.

A maneira como as categorias de formação foram nomeadas revela critérios diferentes utilizados para nomear as disciplinas nos cursos. Algumas categorias enfocam áreas ou subáreas de conhecimento (formação histórica, geográfica, psicológica, social, ambiental, econômica, em hotelaria por exemplo). Outras indicam um tipo de atuação (formação para planejamento, administrativa, prática, pedagógica, para organização de eventos). Em algumas, o critério é a função do que será estudado (formação instrumental, promocional comercial, operacional comercial, científica). Os diferentes critérios revelam o foco em áreas de conhecimento e em intervenções que parecem voltadas apenas para o mercado de trabalho em turismo. Essas não são as melhores maneiras de definir o papel social dos agentes do turismo, pois os comportamentos que deveriam caracterizar a intervenção desses profissionais na realidade social em questão podem não ser ensinados ou são ensinados apenas os comportamentos mais usuais e familiares, restringindo, assim, as possibilidades de atuação e de transformação do campo profissional $^{5}$ (que representa possibilidades mais amplas de intervenção do que no "mercado" de trabalho) que estão inseridos.

5. O termo "campo de atuação profissional", conforme estudo realizado por Rebelatto et al. (1999), é definido pelas possibilidades de trabalho que surgem a partir de necessidades sociais, muitas vezes apenas latentes e não identificadas, diferentemente do termo "mercado de trabalho", que é definido pelas ofertas de emprego existentes.
Aprofundar, em um curso de graduação, aprendizagens relativas a um ou outro aspecto da realidade influenciará toda a atuação dos profissionais no campo para o qual estão se preparando para intervir. O exame dos currículos de quatro cursos de Turismo revela que isso está ocorrendo em relação a esse tipo de formação de nível superior. A quantidade de disciplinas agrupadas nas diferentes categorias criadas para examinar os currículos indica aprofundamentos que podem estar produzindo um tipo de formação muito mais voltada para a atuação em um nível técnico do que em um nível superior de intervenção. Aprofundar o exame dos nomes das disciplinas agrupadas nas diferentes categorias pode fornecer mais informações a respeito do enfoque que está sendo dado à formação dos profissionais em turismo.

A Tabela 2 mostra o detalhamento das categorias de formação instrumental e de formação específica sobre turismo, com os nomes das disciplinas e a ocorrência das mesmas nas diferentes universidades. Ela serve como exemplo da maneira como os nomes foram examinados e representa parte do que foi encontrado como características dos mesmos. De maneira geral, os nomes referem-se a áreas ou subáreas de conhecimento, temas ou categorias de assuntos em diferentes graus de especificidade. Procedimentos ou instrumentos de trabalho também são utilizados como critério para nomear as disciplinas, bem como tipos de atuação ou atividade. Além desses critérios, algumas disciplinas são nomeadas conforme o tipo de exame que a disciplina parece que irá realizar em relação a alguma área de conhecimento ou aspecto da realidade.

As disciplinas de língua estrangeira ou alguma língua específica (Espanhol, Inglês e Esperanto), "Português" ou "Língua Portuguesa" "Estatística" e "Turismo" são exemplos de algumas áreas e subáreas de conhecimento que são utilizadas para nomear as disciplinas nos diferentes cursos de Turismo. Algumas das disciplinas nomeadas conforme áreas e subáreas de conhecimento revelam também, em seus complementos (ou como variações do nome), categorias de assuntos mais específicos (teorias, urbanismo etc.) ou procedimentos e instrumentos de trabalho (oratória, redação, técnica). Categorias de assuntos ou temas específi$\cos$ (teorias, dimensão e dinâmica, higiene e segurança, turismo de...) e procedimentos e instrumentos de trabalho (Informática, linguagens tecnológicas) aparecem também como o único nome de algumas disciplinas. As variações em relação à abrangência são observadas em disciplinas que, no nome, indicam parcelas de alguma área que será estudada (noções, elementos, tópicos). "Lazer e Recreação" é a disciplina que indica um tipo de atividade e o complemento "Consultoria", em outra disciplina, refere-se a um tipo de atuação profissional. Uma das disciplinas revela um "recorte" temporal no tipo de informação que será tratado (contemporâneo) e em outra o "recorte" é geográfico (rural). A 

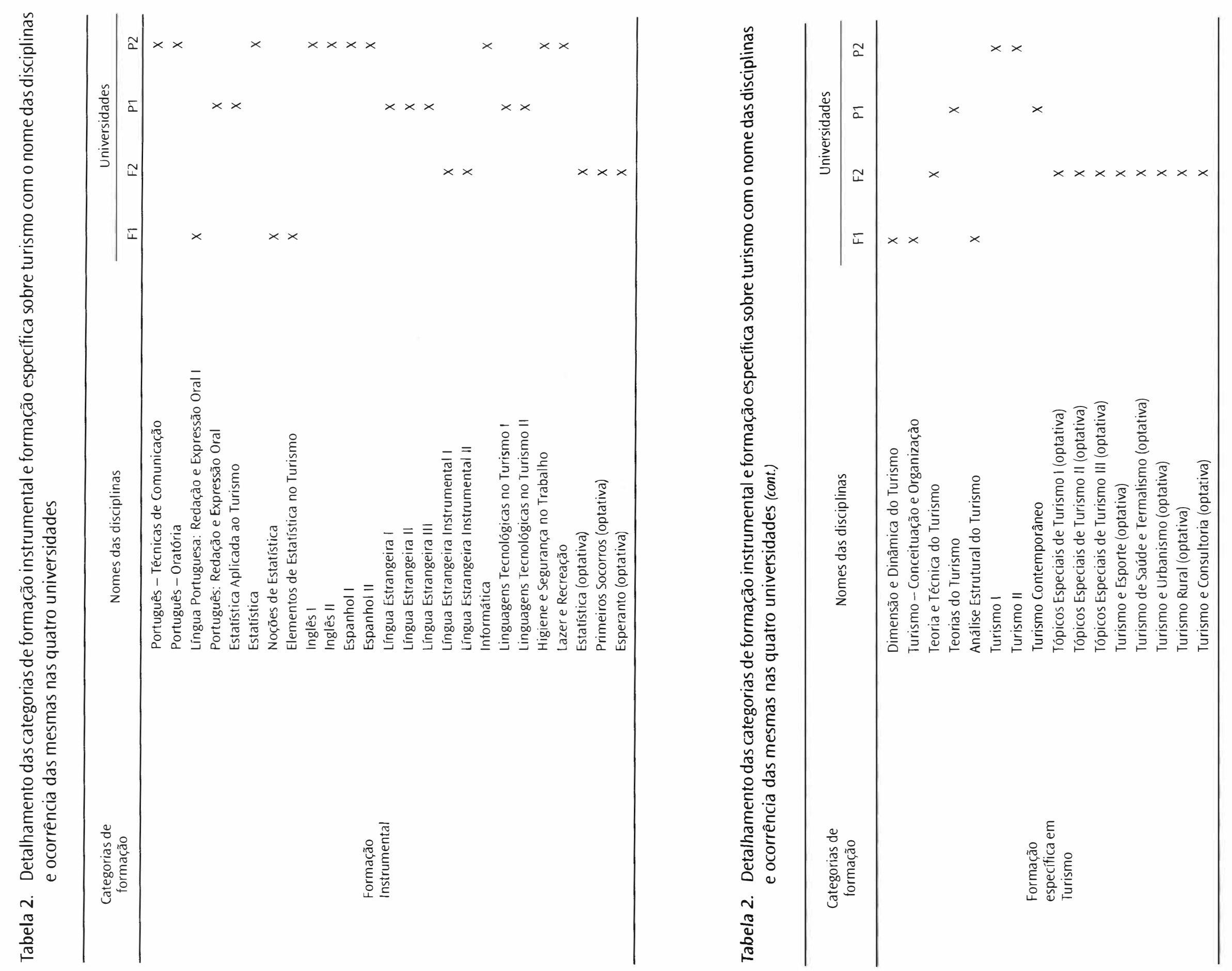
disciplina "Análise Estrutural do Turismo" é homônima do livro escrito por Mário Beni e indica o tipo de exame que será feito em relação ao turismo.

É possível afirmar que a formação em turismo privilegia a exposição de assuntos a serem estudados, lidos ou parafraseados, adotados, "aplicados", ou o domínio de técnicas e procedimentos exigidos para ingresso no mercado de trabalho. Isso porque no conjunto das dezenove categorias de formação criadas a partir do exame dos dados (nomes das disciplinas da grade curricular de quatro cursos de Turismo), é possível identificar nove diferentes critérios utilizados para nomear as disciplinas. Esses critérios podem ser definidos como:

1. áreas e subáreas de conhecimento e temas amplos, isolados ou aplicados (Língua Portuguesa, Estatística e Turismo, por exemplo);

2. categorias de assuntos ou temas restritos, isolados ou aplicados (teorias, urbanismo, esporte, por exemplo);

3. abrangência ou profundidade do estudo de alguma área de conhecimento, assunto ou tema em particular ou em relação a outras áreas de conhecimento, assuntos ou temas (noções, elementos, tópicos, aspectos, por exemplo);

4. "recorte" temporal do estudo de alguma área de conhecimento, assunto ou tema (contemporâneo, antigo, medieval, por exemplo);

5. "recorte" geográfico ou físico do estudo de alguma área de conhecimento, assunto ou tema (rural, brasileiro, na Europa etc.);

6. tipos de procedimentos ou instrumentos de trabalho abrangentes ou específicos de alguma área de conhecimento, assunto ou tema (Informática, linguagens tecnológicas, por exemplo);

7. tipos de atuações ou de atividades, isoladas ou relacionadas a alguma área de conhecimento, assunto, tema, objeto, fenômeno ou lugar (consultoria, recreação, planejamento, agenciamento);

8. tipos de locais de trabalho (agências de viagens);

9. tipo de exame a ser feito em relação a alguma área de conhecimento, assunto ou tema (análise estrutural, por exemplo).

Com base nesses critérios que foram utilizados pelos responsáveis em cada universidade para nomear as disciplinas nos diferentes cursos de Turismo, é possível verificar os tipos de enfoque que estão sendo dados à formação dos agentes do turismo. A Tabela 3 apresenta o número e o percentual dos diferentes critérios de nomeação utilizados nas disciplinas, identificados nas categorias de formação dos quatro cursos de Turismo examinados.

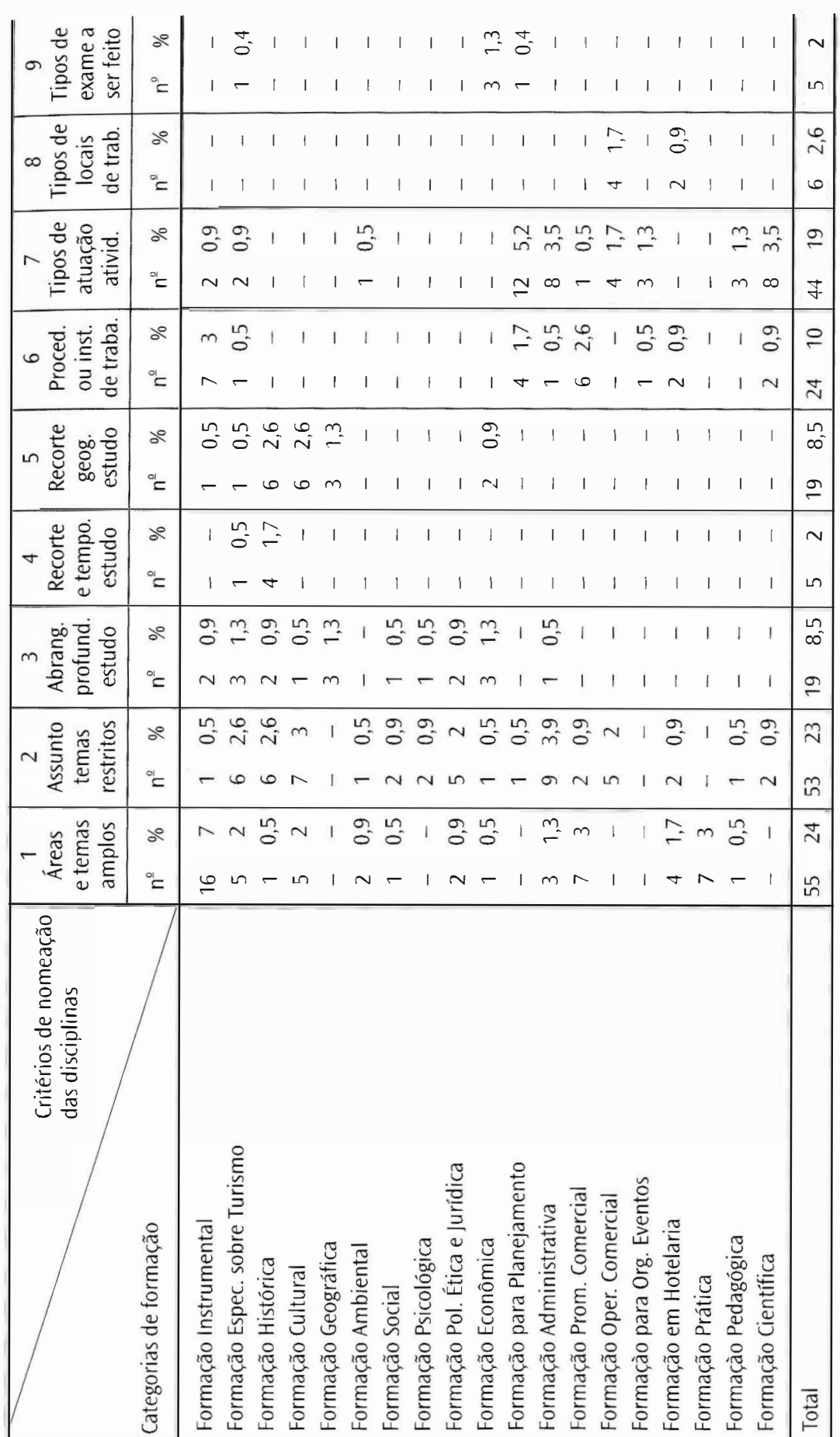


Cinco, dos nove critérios, referem-se a assuntos nos mais diversos graus de abrangência (critérios 1, 2, 3, 4 e 5). Dos outros quatro, um se refere ao estudo de técnicas ou procedimentos de trabalho (critério 6), um se refere a tipos de atuações ou atividades (critério 7), outro se refere a locais de trabalho (critério 8) e um último critério se refere a um tipo de exame que deve ser feito em relação a algo (critério 9) ou a algum tipo de assunto.

O critério 1 , que diz respeito ao foco em áreas ou subáreas de conhecimento ou temas amplos, representa um percentual de $24 \%$ (55 ocorrências) das ocorrências desse tipo de critério de nomeação no conjunto das disciplinas. No critério 2, que enfoca assuntos e temas restritos, foram registradas 53 ocorrências, o que representa $23 \%$ do total de ocorrências dos diferentes critérios.

No critério 3, referente à profundidade ou abrangência do estudo que será realizado na disciplina, foram registradas dezenove ocorrências, o que significa um percentual de $8,5 \%$ do total de critérios utilizados para nomear as disciplinas. O mesmo percentual $(8,5 \%)$ foi registrado em relação ao critério 5 , que diz respeito ao "recorte" geográfico ou físico do estudo que será realizado nas disciplinas. O critério 4 ("recorte" temporal do estudo) foi identificado cinco vezes, bem como o critério 9 (tipo de exame a ser feito); isso significa um percentual de $2 \%$ para a utilização desses critérios no total de ocorrências dos diferentes critérios no nome das disciplinas.

O critério 6 (tipos de procedimentos ou instrumentos de trabalho) foi registrado 24 vezes, o que representa $10 \%$ do total de ocorrências dos diferentes critérios no nome das disciplinas. O critério que diz respeito aos tipos de atuações ou de atividades (critério 7) foi identificado no nome de 44 disciplinas, o que representa um percentual de $19 \%$ do total de ocorrências dos diferentes critérios. O critério 8 , que se refere aos tipos de locais de trabalho onde os profissionais de turismo poderão atuar, foi observado em seis disciplinas, o que significa 2,6\% do total de ocorrências dos diferentes critérios no nome das disciplinas que compõem a formação em turismo.

O nome das disciplinas, na maioria dos casos, está baseado em um conjunto de "coisas" (assuntos, técnicas, linguagens etc.) a serem faladas, lidas, estudadas, repetidas, parafraseadas, adotadas, aplicadas, utilizadas e assim por diante, e não em um conjunto de comportamentos profissionais a ser aprendidos pelos alunos durante a graduação. Isso é verificado a partir da soma dos percentuais registrados nos diferentes critérios que dizem respeito ao enfoque, no nome das disciplinas, em assuntos nos mais variados graus de abrangência (critérios 1,2,3, 4 e 5). Dos critérios utilizados para nomear as disciplinas nos quatro cursos de Turismo examinados, $66 \%$ fazem referência a algum assuntos, contra $19 \%$ de critérios que mencionam alguma atuação ou atividade profissional, indiretamente, na forma de substantivos. Os outros critérios, mesmo sem se referir diretamente a assuntos, enfocam locais de trabalho, tipos de procedimentos ou tipos de exame a serem feitos em ambiente acadêmico (atividades apropriadas à sala de aula), o que não reflete aprendizagens relevantes para a intervenção profissional em relação a determinado "recorte" da realidade na qual o profissional deverá se inserir. Nesse sentido, é importante retomar o que foi problematizado por Paviani et al. (1993) a respeito dos critérios que são tradicionalmente utilizados para planejar e organizar os cursos de nível superior no Brasil: categorias e unidades do conhecimento e não categorias baseadas nos problemas sociais a serem solucionados ou minimizados, ou condutas que constituem procedimentos para lidar com tais tipos de problemas.

Dificuldades relativas à categorização que é feita em uma determinada área de conhecimento ou em um campo de atuação profissional (parcelamento do estudo, tipos de especialização, "recortes" e assim por diante) não parecem ser exclusividade do Turismo. Duran (1983) examina um tipo de enfoque ou aprofundamento que é feito em "Psicologia" e constata que, junto com os demais enfoques existentes, feitos de acordo com diferentes critérios de classificação revelados por termos ("experimental", "social", "do desenvolvimento", "clínica", "patológica" etc.) que acompanham o substantivo "Psicologia", o enfoque que se dedicou a examinar pouco revela a respeito do que é enfocado em tal "parcelamento" do que deve constituir o objeto da Psicologia. Segundo o autor, não existe um sistema de classificação na área, mas apenas um tipo de nomeação "arbitrária e caótica", que dificulta manter uma certa unidade em relação à Psicologia, pois acaba isolando entre si as porções destacadas como se elas tivessem sentido em si mesmas e não mais dentro do contexto de delimitação da Psicologia. Isso contribui para a fragmentação da área e do campo profissional homônimo, além de interferir no que deve ser feito em relação a cada uma das parcelas criadas (Duran, 1983:2). O exame de Duran reflete o que está sendo observado na classificação identificada em relação à formação profissional em turismo. É provável que a divisão criada para facilitar e possibilitar a formação dos profissionais esteja contribuindo para a fragmentação da compreensão desses profissionais em relação à área e, conseqüentemente, para a fragmentação de sua atuação no campo profissional do Turismo ao criar categorias que parecem "coisas" com sentido e significado em si mesmas. Kubo e Botomé (2001a) salientam que os critérios utilizados para classificar o conhecimento, mesmo que fossem adequados, podem ser úteis e significativos para o "almoxarifado do conhecimento" (as bibliotecas, as agências de administração ou de fomento dos processos de produção do conhecimento). Mas os mesmos critérios de classificação não parecem ser úteis quando se trata da organização dos processos e produtos das "oficinas de transformação do conhecimento em capacidade de atuação" (as situações e condições de ensino) das pessoas. O conhecimento é insumo para o trabalho de ensino e não deve ser confundido com o resultado final do mesmo, sob a pena de não haver mais dis- 
tinção entre produzir conhecimento e produzir aprendizagem de outras pessoas em relação ao conhecimento existente.

Postman e Weingartner (1978) chamam a atenção para o poder contido no que denominam de "metáforas naturais". Os autores definem essas metáforas como os conceitos criados em um meio lingüístico que os aprova e afirmam que elas possibilitam uma percepção restrita da realidade, o que, conseqüentemente, possibilita tipos de comportamentos altamente limitados. Quando as categorias criadas em função de diferentes "recortes" existentes no universo de uma área de conhecimento ou campo de atuação (nesse caso, o Turismo) parecem revelar uma parcela independente desse universo, elas são transformadas nessas "metáforas naturais" e comprometem a percepção da relação entre essas parcelas e o todo. Cada "pedaço" de uma determinada realidade é transformado em "o" pedaço e "a" verdade, o que dificulta ou impede o questionamento desses "pedaços" e também restringe a percepção das características e possibilidades de atuação profissional no universo do turismo. As armadilhas das taxonomias como entidades ou explicações ainda não parecem ser suficientemente percebidas ou identificadas.

Esses mesmos autores problematizam os termos utilizados para descrever a realidade. Geralmente são usados substantivos que nomeiam e "coisificam" os processos em vez de termos que os revelem ou descrevam de fato. Nomear os processos da realidade, de maneira a "coisificá-los", pode ser inadequado e enganador, além de afastar as pessoas dessa realidade, pois compromete sua percepção e a maneira como irão se relacionar com ela. Conforme Postman e Weingartner (1978: 103), "fazemos a realidade que percebemos".

Alguns exemplos podem ilustrar o que está sendo problematizado. São usados termos como "ensino", para designar um tipo de atuação dos professores, e "aprendizagem", para designar o que deve ocorrer com os alunos. Esses substantivos isolam cada um desses processos como se eles não tivessem relação entre si. Dessa forma, os professores ensinam, por exemplo, mesmo se os alunos não aprendem. Ensinar e aprender são dois processos que dependem um do outro, como foi minuciosamente demonstrado por Kubo e Botomé (2001a), e nomeá-los como substantivos (ensino e aprendizagem) encobre essa relação. Quando se trata das disciplinas dos cursos de Turismo, termos como "teoria" "espaços turísticos", "paisagens turísticas", "planejamento", "agenciamento", "dimensão e dinâmica do...", "museologia", entre outros, são exemplos da transformação do conhecimento "na" verdade, ou então da "coisificação" de processos que dependem da intervenção humana e de um determinado contexto para que possam existir e ocorrer. A maneira como as disciplinas são nomeadas nos cursos de Turismo permite que equívocos como esses ocorram, além de limitar a percepção de professores e alunos em relação ao que devem fazer.

\section{Conclusão}

A característica geral dos nomes das disciplinas aparece nas categorias criadas para organizar e interpretar os dados coletados. As categorias refletem os diferentes critérios utilizados para nomear as disciplinas e, conseqüentemente, a pouca clareza em relação à função de cada uma para o desenvolvimento de comportamentos profissionais significativos para a sociedade em relação ao turismo. Conforme foi observado, um primeiro conjunto de categorias de formação reflete áreas ou subáreas de conhecimento. Em um segundo conjunto, as categorias refletem atuações típicas do mercado de trabalho do turismo. E um terceiro conjunto parece refletir a função do que será estudado para a intervenção nesse campo profissional. Que categorias seriam as mais adequadas para orientar o planejamento e organização dos cursos de Turismo, no sentido de torná-los mais efetivos na capacitação de pessoas para solucionar problemas sociais, para minimizar ou suprir as necessidades da sociedade em relação ao turismo? Paviani et al. (1993) indicam uma possibilidade para isso, quando destacam que as categorias dos problemas, necessidades e características sociais que precisam da intervenção profissional seriam mais apropriadas do que as categorias da organização do conhecimento, para serem utilizadas em um contexto de transformação do conhecimento em capacidade de atuar frente à realidade, ou seja, em processos de ensino e de aprendizagem. Mas como poderia ser um projeto de curso baseado nesses pressupostos? Que características fundamentais deve ter o currículo de um curso baseado no que o profissional precisa aprender a fazer em relação à realidade e não apenas baseado no "conteúdo" que ele precisa "dominar"?

Uma possibilidade de currículo baseado nos comportamentos profissionais necessários para a atuação foi proposta por Botomé e Kubo (200lb), em um trabalho realizado com o apoio do Conselho Regional de Psicologia de Santa Catarina. Os autores, com base nas Diretrizes Curriculares que estavam em processo de aprovação, apresentaram uma outra possibilidade na qual aprofundam, complementam e especificam aspectos presentes nas diretrizes originais, enfocando a capacidade de atuar do psicólogo. Nessa proposição, os autores definem, com base em três metas fundamentais do ensino de graduação (ensinar a produzir conhecimento, ensinar a ensinar outras pessoas e ensinar a intervir diretamente sobre os fenômenos), treze categorias de formação que refletem as diferentes dimensões da intervenção profissional ou classes de comportamentos mais específicos que devem ser aprendidas durante a graduação em Psicologia e que são importantes para que as três classes mais gerais de comportamentos (produzir conhecimento sobre fenômenos, ensinar outras pessoas a lidar com fenômenos e intervir diretamente sobre fenômenos) se concretizem como atuação. Essas categorias têm como base o conhecimento 
existente em diversas áreas, mas não se restringem a ele, pois revelam uma maneira de utilizar o conhecimento para desenvolver comportamentos importantes para a vida profissional e significativos para a sociedade.

As categorias propostas por Botomé e Kubo (2001b) como parte das diretrizes para os cursos de Psicologia refletem diferentes dimensões da atuação profissional e são baseadas na descrição dos processos comportamentais fundamentais que caracterizam cada um dos enfoques relevantes nesses diferentes tipos de formação, em vez de se basearem no tipo de conhecimento que é produzido pelas áreas ou subáreas que, em alguns casos, nomeiam as categorias. No Quadro 1 estão apresentadas as treze categorias propostas pelos autores e uma descrição geral da classe de comportamentos que deve constituir cada uma delas. É possível perceber que, apesar de serem categorias propostas para os cursos de Psicologia, elas se aplicam perfeitamente ao campo profissional do Turismo, bem como a tantos outros campos de atuação.

A proposta de diretrizes curriculares para os cursos de Psicologia, formulada por Botomé e Kubo (2001b), além de sinalizar uma possibilidade de construção do currículo com base nos tipos de comportamentos que precisam ser aprendidos em um curso de graduação, pode ser aplicada em outras áreas de conhecimento para capacitar os alunos a atuarem de acordo com as características do campo profissional geralmente homônimo a tal área. Isso porque os autores descrevem os processos comportamentais que caracterizam a atuação nas diferentes áreas de conhecimento ou nas diferentes disciplinas que nomeiam as categorias de formação possíveis em um curso de graduação em vez de enfocar o conhecimento produzido nas mesmas. Essa proposta não esgota as possibilidades de melhoria em relação aos processos de planejamento e organização do ensino. Ela é, antes de mais nada, uma concepção de como precisa ser o processo de planejar o ensino superior: partir do que precisa ser aprendido como comportamento para atuar profissionalmente em relação a necessidades sociais e não apenas partir do conhecimento que precisa ser "transmitido" para o aluno.

Em primeira análise, não são as competências ou os comportamentos profissionais a ser aprendidos para intervir no campo do Turismo, o que está sendo provocado pela formação de graduação nesse campo. O foco em categorias de assuntos e, ocasionalmente, comportamentos "escondidos" em categorias de assuntos, percebido no nome das disciplinas que compõem os cursos, provavelmente está formando profissionais com um repertório de atuação limitado e pouca qualificação para um efetivo desenvolvimento do campo profissional. Isso caracteriza muito mais um tipo de atuação de nível técnico do que a atuação de nível superior (que vai muito além dessa dimensão) necessária para intervir em relação às características, necessidades e problemas pertinentes a um determinado
Quadro 1. Categorias de formação propostas por Botomé e Kubo (2001) como diretrizes para os cursos de graduação em Psicologia

1. Formação técnica: aprender a utilizar com correção e precisão o instrumental de trabalho do psicólogo e o conhecimento existente relacionado ao exercício da profissão.

2. Formação histórica: aprender a avaliar e integrar as múltiplas contribuiçōes do conhecimento produzido em diferentes épocas e contextos.

3. Formação antropológica: aprender a relacionar-se com outras culturas.

4. Formação filosófica: aprender a pensar, a raciocinar com correção.

5. Formação científica: aprender a aprender e aprender a produzir conhecimento científico.

6. Formação pedagógica e de liderança: aprender a educar e liderar.

7. Formação social: aprender a relacionar-se com outras pessoas.

8. Formação política: aprender a equilibrar as relaçōes de poder na sociedade.

9. Formação de empreendedor: aprender a empreender.

10. Formação ética: aprender a garantir a dimensão ética na atuação profissional (garantir benefícios efetivos, constantes e duradouros).

11. Formação religiosa: aprender a lidar com o absoluto, o significado da vida, com os processos de sacralização.

12. Formação estética: aprender a avaliar a satisfação e o prazer que produz com seu trabalho e sua atuação profissional.

13. Formação Psicológica: aprender a lidar com processos comportamentais no seu contexto de vida e atuação.

contexto social. A diferenciação entre formação técnica e formação de nível superior não é um julgamento de valor, mas algo que já é conhecido e precisa ser considerado. Caso contrário, as universidades estarão formando apenas técnicos, coisa que cursos mais rápidos e menos custosos podem fazer. Esse exame parcial, realizado a respeito dos nomes das disciplinas que compõem os cursos de Turismo, é um primeiro passo para verificar as distorções e possibilidades em relação à formação profissional nesse campo. O estudo e a proposição de diretrizes curriculares elaborados por Botomé e Kubo (2001b) podem servir como um exemplo ou uma base para o exame dos currículos dos cursos de Turismo em relação a cada categoria de maneira mais específica.

\section{Referências bibliográficas}

ANSARAH, Marília Gomes dos Reis. 2002. Formação e capacitação do profissional em turismo e hotelaria: reflexōes e cadastro das instituiçōes educacionais no Brasil. São Paulo: Aleph.

BOTOMÉ, Sílvio Paulo. 1980. Objetivos comportamentais no ensino: a contribuição da análise experimental do comportamento. Dissertação (Mestrado) - Programa de Pós-Graduação em Psicologia Experimental, Universidade de São Paulo, São Paulo. 
1988. Em busca de perspectivas para a Psicologia como área de conhecimento e como campo profissional. In: Brasil - Conselho Federal de Psicologia. Quem é o psicólogo brasileiro? São Paulo: Edicon.

. (Org.). 2000. Diretrizes para o ensino de graduação: o projeto pedagógico da Pontifícia Universidade Católica do Paraná. Curitiba: Ed. Universitária Champagnat.

. 2001a. Sobre a noção de comportamento. In: FELTES, H. P. M. \& ZILLES, U. (Orgs.). Filosofia: diálogo de horizontes. Porto Alegre: edipucrs; Caxias do Sul: eduCs.

. \& KUBO, Olga Mitsue. 2001b. Proposta de minuta para as diretrizes curriculares. Texto elaborado como material de estudo para os seminários promovidos junto ao Conselho Regional de Psicologia de Santa Catarina, como coordenadores dos cursos de Psicologia do Estado de Santa Catarina. Texto não publicado.

2002. Responsabilidade social dos programas de pós-graduação e formação de novos cientistas e professores de nível superior - problemas e perspectivas para instituições de ensino superior. In: Desafios e perspectivas do ensino de pós-graduação no setor particular. Brasília: FUNADESP, maio.

DURAN, Álvaro Pacheco. 1983. Psicologia social: entre a microscopia e a macroscopia do social. Trabalho apresentado no Simpósio de Questōes Atuais da Psicologia Social durante a 35ª reunião anual da SBPC. Belém. Texto não publicado.

GAGNÉ, Robert M. 1971. Como se realiza a aprendizagem. Rio de Janeiro: Livros Técnicos e Científicos.

KUBO, Olga Mitsue \& BOTOMÉ, Sílvio Paulo. 2001. Ensino-aprendizagem: uma interação entre dois processos comportamentais. InterAÇÃO. Curitiba: Departamento de Psicologia da UFPR, v. 5, jan./dez.

MAGER, Robert F. 1987. A formulação de objetivos de ensino. 7. ed. Rio de Janeiro: Globo.

PAVIANI, Jaime \& BOTOMÉ, Sílvio Paulo. 1993. Interdisciplinaridade: disfunções conceituais e enganos acadêmicos. Caxias do Sul: EDUCS.

POSTMAN, Neil \& WEINGARTNER, Charles. 1978. Contestação - nova fórmula de ensino. 4. ed. Rio de Janeiro: Expressão e Cultura.

REBELATTO, José Rubens \& BOTOMÉ, Ślvio Paulo. 1999. Fisioterapia no Brasil: fundamentos para uma ação preventiva e perspectivas profissionais. São Paulo: Manole.

SPINELLI, Sara M. 2002. A importância da formação profissional em turismo. In: SHIGUNOV NETO, Alexandre \& MACIEL, Lizete S. B. (Orgs.). Currículo e formação profissional nos cursos de turismo. Campinas: Papirus.

SHIGUNOV NETO, Alexandre \& MACIEL, Lizete S. B. (Orgs.). 2002. Currículo e formação profissional nos cursos de turismo. Campinas: Papirus.

TRIGO, Luiz Gonzaga. 1998. A sociedadepós-industrial e o profissional em turismo. Campinas: Papirus.

Recebido em 06/10/2004.

Aprovado em 18/10/2004. 